\section{ORTHOTOPIC CARDIAC TRANSPLANTATION WITH DIRECT CAVAL ANASTOMOSIS: IS IT THE OPTIMAL PROCEDURE?}

Total excision of the right atrium with a minimal cuff of left atrium remaining around the four pulmonary veins, followed by direct anastomoses on venae cavae, has been proposed as an alternative to the standard procedure described by Shumway and Lower for orthotopic cardiac transplantation. To investigate whether this "anatomic" transplantation should be proposed as the optimal procedure, we prospectively randomized 78 patients having 81 procedures since 1991 into two groups: group I, standard transplantation ( $n=40$ ), and group II, "anatomic" transplantation ( $n=41)$. The two groups were statistically similar in recipient age, sex, weight, disease, and status at the time of transplantation. Also similar were donor age, sex, weight, and drug dependency at the time of harvesting. All patients could be weaned from cardiopulmonary bypass with comparable graft ischemic times (group I, $136 \pm 46$ minutes; group $\Pi$, $138 \pm 51$ minutes). Immediate recovery of sinus rhythm occurred in 20 cases of group I and 36 cases of group II. Delayed recovery of sinus rhythm in the first postoperative week occurred in 15 cases of group I and 5 cases of group II. Persistence of atrial arrhythmia occurred in 5 cases of group I and never in group $I$. These differences were highly significant $(p<0.001)$. Postoperative hemodynamics showed a higher cardiac index at day 1 in group II (4.12 $\pm 0.85 \mathrm{~L} / \mathrm{min}$ per square meter) than in group I (3.77 \pm 0.65 $\mathrm{L} / \mathrm{min}$ per square meter) $(p=0.04)$. There were 13 early deaths in group I and 8 early deaths in group II. One death in group I was related to an acute atrioventricular block at 3 weeks with no evidence of cardiac rejection at histologic examination. Two patients in group I (5\%) required definitive pacemaker implantation for prolonged sinus node dysfunction. Echocardiographic and Doppler studies of survivors have been performed 2 to 3 months after transplantation. Right atrial area was significantly reduced $(p<$ 0.01) in group $I\left(18 \pm 4.7 \mathrm{~cm}^{2}\right)$ versus group $I\left(24 \pm 7 \mathrm{~cm}^{2}\right)$, as was left atrial area (group I, $24 \pm 4.5 \mathrm{~cm}^{2}$; group II, $\left.20 \pm 5 \mathrm{~cm}^{2}\right)(p=0.01)$. Mild tricuspid regurgitation was observed in $82 \%$ of group I patients versus $57 \%$ of group II patients $(p<0.05)$, inasmuch as mitral regurgitation was comparable (71\% in group I, $67 \%$ in group II). Exercise performance realized in the same period showed no difference in peak oxygen consumption between the two groups. Even the slight improvement in morbidity should lead surgeons to consider this alternative technique as the optimal procedure, because the technique appears simple and safe. (J THORAC CARDIOVASC SuRG 1995;109:731-7)

P. H. Deleuze, MD, C. Benvenuti, MD, J. P. Mazzucotelli, MD, C. Perdrix, MD,

P. Le Besnerais, MD, A. Mourtada, MD, M. L. Hillion, MD, J. F. Patrat, MD,

P. Jouannot, MD, and D. Y. Loisance, MD, Créteil, France
T he technique of orthotopic heart transplantation has been well established for more than 30 years, based on the first description by Lower, Stofen, and

From the Cardiothoracic Surgery and Cardiac Rehabilitation Center, CNRS URA 1431 "Thérapeutiques Substitutives du Coeur et des Vaisseaux" and Association Claude Bernard (Pr.D. Loisance), C.H.U. Henri Mondor and Hospital Albert Chennevier, 94000 Créteil, France.

Received for publication July 25, 1994.

Accepted for publication Nov. 28, 1994.

Address for reprints: Philippe Deleuze, MD, Chirurgie Thoracique et Cardiaque, CHU Henri Mondor, 51 av. du Maréchal De Lattre de Tassigny, 94000 Créteil, France.
Shumway. ${ }^{1}$ Nevertheless, anastomoses of donor to recipient atria according to this technique create large atrial cavities with abnormal geometry. This abnormal geometry has been demonstrated to be responsible for tricuspid and mitral regurgitation ${ }^{2,3}$ and for arrhythmias resulting from sinus node injury. ${ }^{2,4}$ The risk of atrial septal aneurysms or atrial thrombus formation is certain. ${ }^{2,5}$ Because of these problems, some authors ${ }^{6,7}$ proposed a more anatomic surgical technique with complete excision of

Copyright (C) 1995 by Mosby-Year Book, Inc.

$0022-5223 / 95 \$ 3.00+0 \quad 12 / 1 / 62364$ 
the recipient's atria and direct anastomoses on the left pulmonary veins, right pulmonary veins, inferior venae cavae (IVC), and superior venae cavae (SVC). No technical complications occurred, but the benefit of this procedure on clinical outcome has not been demonstrated.

After a few trials with this six-anastomosis technique, we devised a more optimal alternative, performing a unique anastomosis on a small cuff of the left atrium together with bicaval anastomoses. ${ }^{8,9}$ We present here a prospective, randomized study, started in 1991, on orthotopic cardiac transplantation using the standard technique ${ }^{1}$ versus direct anastomoses of the venae cavae.

\section{Patients and methods}

Patient groups. From the beginning of 1991 to the end of 1993, 81 orthotopic cardiac transplantations have been performed in our institution in 78 patients. Patients were randomized alternately at the time of the operation into two groups according to surgical technique: in group I $(n=40)$, cardiac transplantation was performed the standard way; in group II $(n=41)$, direct anastomoses of venae cavae and minimal recipient left atrial cuff were used. In our technique, we used a single anastomosis on the left atrium, which was trimmed on the recipient side to a minimal cuff collecting the four pulmonary veins, instead of separate anastomoses on the left pulmonary veins and right pulmonary veins. As shown in Table $I$, the two groups were similar with regard to recipient age, sex, disease, previous operation, status at the time of transplantation, and for donor age, sex, weight, and hemodynamic stability.

\section{Surgical technique}

Donor. Harvesting of the donor heart has not been changed for this alternative technique and included in all cases a segment of the SVC beyond the azygos vein and $1 \mathrm{~cm}$ of the IVC. The left atrium, aorta, and pulmonary artery were trimmed the standard way, depending at times on simultaneous lung or bilateral lung harvesting.

In group I, the donor right atrium was opened along a posterior line joining the two vena caval openings away from the sinus node. In group II, the right side of the heart was left intact.

Recipient. Aortic cannulation was done near the emergence of the brachiocephalic artery. Venous cannulation was performed posteriorly in the right atrium in group I and in each vena cava, to leave a remnant of the vessel for anastomoses, in group II. In this latter group, the right atrium was totally resected, leaving the origin of the IVC and SVC. The left atrium was trimmed to leave a $1 \mathrm{~cm}$ margin of atrial cuff around all four pulmonary veins.

Heart transplantation. In group I, left atrial, septal, and right atrial anastomoses were conducted in the standard fashion with 4-0 polypropylene continuous sutures. In group II, the left atrial cuff was anastomosed first, with a 4-0 polypropylene continuous suture. The septum was totally excised with the right atrium. The IVC was anastomosed with a 5-0 polypropylene continuous everting suture. The SVC was then anastomosed the same way (Fig. 1). We considered everting sutures to be of vital importance to afford a perfect intravascular lining of the anastomosis and to avoid thrombus formation. In case of a previous sternotomy, direct vena caval anastomoses appeared easier than the standard technique, because the venae cavae themselves were always free of adhesions. In case a heterotopic or orthotopic assist device was being used, the bicaval anastomosis technique again appeared more convenient because the right and left atria were impaired by device cannulas or cuffs at the time of transplantation, and they could be removed en bloc by the cardiectomy.

Postoperative assessment. Follow-up was $100 \%$ complete, from 4 to 37 months. Early mortality was defined as death occurring before 1 month after the operation. In all surviving patients cardiac hemodynamic data were monitored with a Swan-Ganz catheter (Baxter Healthcare Corp., Edwards Division, Santa Ana, Calif.) during the first 2 postoperative days. Then right atrial pressure was measured at the time of the first endomyocardial biopsy (day 8).

Echocardiographic technique. Two-dimensional echocardiograms and Doppler recordings were performed with a Hewlett-Packard Sonos 1000 Instrument (Hewlett Packard Company, Andover, Mass.) using a $2.5 \mathrm{MHz}$ transducer. Continuous electrocardiographic tracings were recorded throughout each procedure. Apical two- and four-chamber views were obtained according to the criteria of the American Society of Echocardiography and recorded on a videotape.

Measurements were performed at the time of maximal atrial dimension or at the end of the $T$ wave. Right and left atrial areas were measured by planimetry in the four-chamber apical long-axis view. Mitral (or tricuspid) regurgitation was defined as the presence of systolic flow disturbance directed into the left (or right) atrium behind mitral (or tricuspid) valve leaflets on pulsed wave Doppler echocardiograms.

Exercise testing. Twenty-five patients in group I and 21 patients in group II had exercise studies performed $52 \pm$ 11 days (28 to 80 days) after transplantation. Patients exercised using a modified Bruce protocol in the postabsorptive state. Mixed expired oxygen, carbon dioxide, and expired volume were determined at rest and throughout exercise by means of a metabolic cart. Peak oxygen consumption was defined as the highest value of the oxygen consumption reached at the end of the exercise.

Holter monitor studies were obtained for all patients in the same period.

Statistical analysis. Results were expressed as the mean \pm one standard deviation. Data were compared with Student's $t$ test for quantitative data and $\chi^{2}$ test for qualitative data. A value of $p<0.05$ was considered statistically significant.

\section{Results}

Early postoperative course. All transplantations had an immediately favorable outcome in the operating room. All hearts but two defibrillated spontaneously after unclamping of the aorta in each group. Ischemic time of the graft was similar in the two 
Table I. Comparison of recipient and donor characteristics in 81 heart transplantations in 78 patients: group I (standard) and group II (caval anastomoses)

\begin{tabular}{lccc}
\hline & $\begin{array}{c}\text { Group I } \\
(n=40)\end{array}$ & $\begin{array}{c}\text { Group II } \\
(n=41)\end{array}$ & $\begin{array}{c}\text { Statistical } \\
\text { significance }\end{array}$ \\
\hline Recipient & & & NS $(p=0.06)$ \\
Age (yr) & $49.8 \pm 8$ & $45.6 \pm 11$ & NS $(p=0.25)$ \\
Sex (M:F) & $32: 8$ & $34: 4^{*}$ & NS $(p=0.5)$ \\
Weight (kg) & $69.6 \pm 14$ & $71.7 \pm 14$ & NS $(p=0.30)$ \\
Etiology & 23 & 19 & NS $(p=0.20)$ \\
Dilated & 15 & 16 & NS $(p=0.20)$ \\
Ischemic & 2 & 6 & NS $(p=0.42)$ \\
Others & 12 & 17 & NS $(p=0.50)$ \\
Previous sternotomy & 29 & 24 & NS $(p>0.50)$ \\
Status at time of transplantation & 11 & 17 & NS $(p>0.50)$ \\
Home & & $34 \pm 9.8$ & $27: 14$ \\
In hospital & $32.1 \pm 11.5$ & $68.7 \pm 11.8$ & NS $(p>0.50)$
\end{tabular}

NS, Not significant.

*Three patients underwent retransplantation.

groups (Table II). Patients received isoprenaline intravenously as part of our protocol for a minimum of 5 days. Dobutamine infusion was given occasionally, in the same ratio in both groups, depending more on the quality of the graft than on the ischemic time. There was no difference between the two groups in the delay of extubation (Table II).

A significant difference in sinus rhythm was observed between the two groups (Table II): in group I, 20 patients had sinus rhythm on the electrocardiogram taken in the immediate postoperative period, 15 patients regained sinus rhythm in the first postoperative week, and 5 patients never regained sinus rhythm. In group II, 36 patients returned spontaneously to sinus rhythm in the operating room and 5 patients only after a delay of a few days $(p<0.001)$; no patients had definitive arrhythmia.

Hemodynamic parameters recorded on postoperative days 1 and 2 are summarized in Tables III-A and III-B. There were no differences between the two groups in mean aortic pressure or right and left atrial pressures. Cardiac index was significantly higher on day 1 in group II $(p=0.04)$. Mean pulmonary artery pressure was significantly lower and heart rate significantly higher on days 1 and 2 in group II inasmuch as isoprenaline infusion was comparable.

Right-sided hemodynamic data obtained on day 8 , during the first endomyocardial biopsy, showed similar right atrial pressures in both groups: $9 \pm 6$ $\mathrm{mm} \mathrm{Hg}$ in group I and $8 \pm 6 \mathrm{~mm} \mathrm{Hg}$ in group II, but no sign of inflow obstruction related to caval anastomoses was ever detected.

Early mortality. Overall early mortality was $25 \%$. Thirteen patients in group I and eight patients in group II died in the first postoperative month of variable causes, mainly sepsis with multiorgan failure. The difference between groups was not statistically significant $(p=0.25)$. One death in group I was related to an acute atrioventricular block on day 22 , without evidence of cardiac rejection on histologic examination.

Echocardiographic analysis. Eight echocardiographic studies in surviving patients were rejected because of inadequate technical quality ( 5 in group I, 3 in group II).

Right atrial area was significantly less in the group with direct caval anastomosis, $18.5 \pm 4.7 \mathrm{~cm}^{2}(10.5$ to $30 \mathrm{~cm}^{2}$ ), than in the group with standard anastomosis, $24.10 \pm 6.9 \mathrm{~cm}^{2}$ (15 to $\left.44.3 \mathrm{~cm}^{2}\right)(p=0.004)$. 


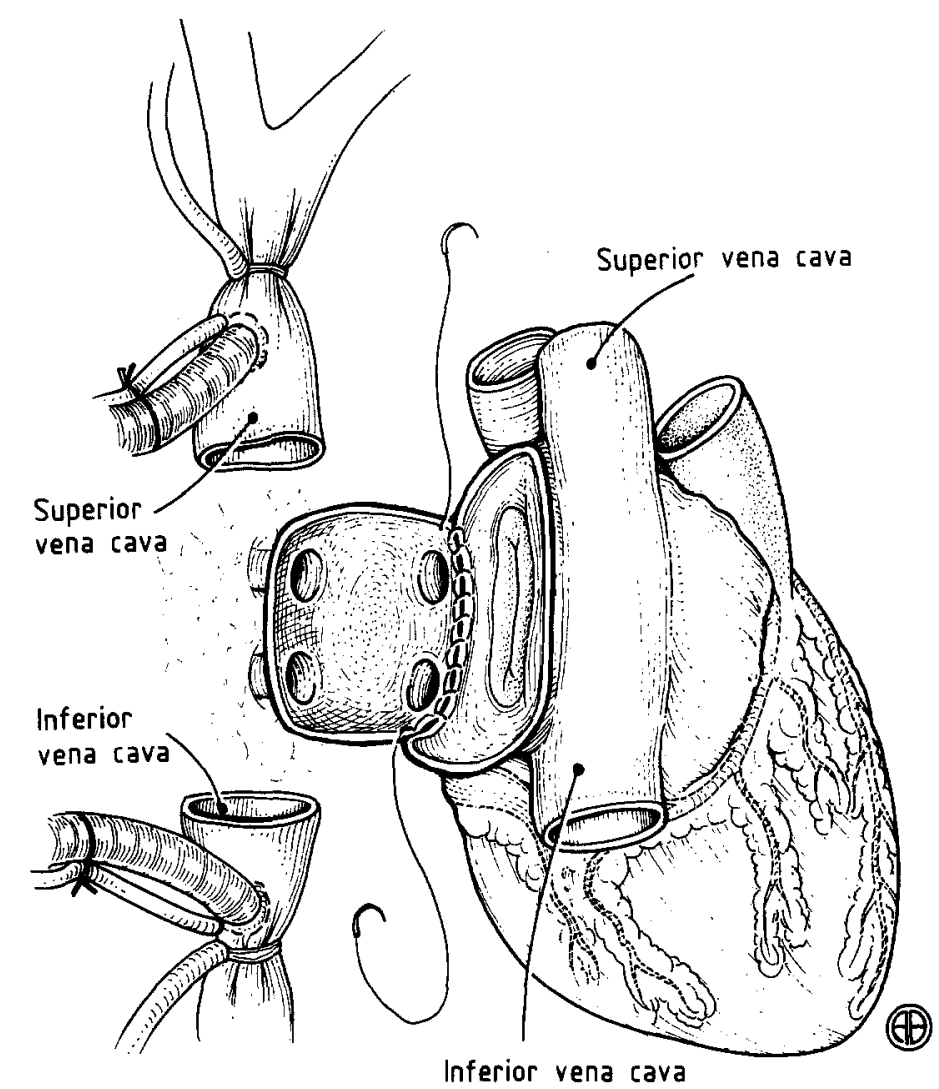

Fig. 1. Schema of the surgical alternative technique in patients of group II (bicaval anastomosis). Right atrium of donor heart is kept intact. Anastomosis on each vena cava is conducted with a 5-0 polypropylene everting continuous suture.

Left atrial area in the group with caval anastomosis was also significantly less than that of the group treated with the standard technique: $20.02 \pm 4.9 \mathrm{~cm}^{2}$ (10.7 to $32 \mathrm{~cm}^{2}$ ) in group II and $24.01 \pm 4.48 \mathrm{~cm}^{2}$ (17.10 to $\left.36.7 \mathrm{~cm}^{2}\right)$ in group I $(p=0.01)$. The linear regression analysis demonstrated a significant correlation between left and right atrial area in each group (group I: $r=0.68, p=0.001$; group II: $r=$ $0.73, p=0.0001)$.

Mild tricuspid insufficiency was observed in $82 \%$ of patients in group I and $57 \%$ of patients in group II $(p=0.02)$. Mitral regurgitation was present in $71 \%$ and $67 \%$ of analyzed patients, respectively, in group I and group II (difference not significant). No obstruction of the SVC or IVC was ever detected in group II at Doppler study.

Exercise testing. Available peak oxygen consumptions were obtained 1 to 3 months after the operation in 25 patients of group I and 21 patients of group II. Peak oxygen consumption was not significantly different between groups: $22.0 \pm 4.2 \mathrm{ml} / \mathrm{kg}$ per minute ( 15 to $32 \mathrm{ml} / \mathrm{kg}$ per minute) in group I; $23.7 \pm 5.3 \mathrm{ml} / \mathrm{kg}$ per minute (14 to $36 \mathrm{ml} / \mathrm{kg}$ per minute) in group II.

Exercise-induced arrhythmia was not observed.

Electrophysiologic study. Twenty-four-hour Holter monitor recording demonstrated sinus node dysfunction necessitating definitive pacemaker implantation in two patients of group I (5\%), at days 50 and 58. No pacemaker use was necessary in group II, with all patients having sinus rhythm.

\section{Discussion}

Orthotopic transplantation with caval anastomosis, recently proposed ${ }^{6}$ as an alternative to the standard procedure, is controversial, and preliminary studies did not demonstrate any functional benefit from this alternative technique. ${ }^{70}$ These papers have shown the feasibility and safety of the method and suggested anatomic and physiologic advantages related to the preservation of normalsized atrial cavities. ${ }^{2-4}$ Nevertheless, they were es- 
Table II. Immediate postoperative data in 81 heart transplantations: group I (standard) and group II (caval anastomoses)

\begin{tabular}{|c|c|c|c|}
\hline & $\begin{array}{c}\text { Group I } \\
(n=40)\end{array}$ & $\begin{array}{l}\text { Group II } \\
(n=41)\end{array}$ & $\begin{array}{c}\text { Statistical } \\
\text { significance }\end{array}$ \\
\hline Ischemic time of the graft (min) & $136 \pm 46$ & $138 \pm 51$ & $\mathrm{NS}(p=0.50)$ \\
\hline Extubation time (hr) & $40 \pm 38$ & $62 \pm 80$ & $\mathrm{NS}(p=0.10)$ \\
\hline \multicolumn{4}{|l|}{ Sinus rhythm } \\
\hline Immediate & 20 & 36 & \\
\hline Delayed (a few days) & 15 & 5 & $p<0.001$ \\
\hline Never & 5 & 0 & \\
\hline Early death $(<1 \mathrm{mo})$ & 13 & 8 & NS $(p=0.25)$ \\
\hline
\end{tabular}

$N S$, Not significant

sentially descriptive ${ }^{6-9}$ and were argued because clear superiority of the method could not be demonstrated, owing to the small number of patients and lack of follow-up. The need for further investigations appeared necessary.

Our prospective randomized study in 81 transplantations was intended to evaluate the benefits of this modification, assessed by clinical, hemodynamic, echocardiographic, and exercise investigations.

The results of the present study showed that orthotopic heart transplantation with bicaval anastomoses was a safe procedure without surgeryrelated complications. It did not increase the graft ischemic time. Furthermore, sinus rhythm was obtained immediately in $90 \%$ of this group and in the remaining $10 \%$ before day 7 . Sinus node dysfunction was never observed when caval anastomoses were performed. By contrast, $5 \%$ of patients operated on with the standard procedure had sinoatrial block necessitating definitive pacemaker implantation, and one patient of this group had an acute sinus dysfunction and died suddenly on day 22 , without evidence of rejection at histologic examination.

Hemodynamic study on postoperative day 1 showed a slight improvement in cardiac index in transplantations with bicaval anastomoses, probably related to the higher number of patients in sinus rhythm on day 1 in this group versus the standard group and thus to a higher number of patients benefiting from donor atrial contraction. A slight increase in heart rate and decrease in mean pulmonary artery pressure in the "anatomic" group on days 1 and 2 while isoprenaline administration was the same might have the same explanation. These differences were not been pointed out in a previous hemodynamic study of the same kind, ${ }^{10}$ but the number of patients included were much smaller.

At later echocardiographic examination, the "an- atomic" transplantation was associated with less incidence of tricuspid regurgitation whereas the right and left atrial areas looked significantly smaller. Nevertheless, no difference in exercise performance could be identified.

The early mortality (day 30 ) was not significantly different in the two groups even though a trend toward a decrease in mortality appeared in the "anatomic" group. The 25\% early mortality looks high but remains stable in our series at 1 year and compares favorably with that of the France Transplant Registry, ${ }^{11}$ which reported $68 \%$ survival at 1 year. Indications for heart transplantation are probably more lenient in France than in the United States. In our series 28 patients were already in the hospital at the time of transplantation, 10 receiving mechanical circulatory support, both of which are bad prognostic signs. ${ }^{12}$

This alternative technique will not strongly modify the course of heart transplantation, because the Shumway-Lower technique ${ }^{1}$ has been performed on thousands of patients with excellent results. Nevertheless, if the quality of the immediate postoperative outcome can be slightly improved and if morbidity can be lowered, this technique should be considered.

This alternative technique is feasible and safe from a surgical point of view. ${ }^{6-10}$ It eliminates the anatomic abnormalities of the initial technique, including enlargement of atrial cavities and protusion of atrial suture lines with the high risk of tricuspid regurgitation, atrial thrombus formation, or atrial septal aneurysm. ${ }^{2-5}$ From a surgical viewpoint, in certain cases such as heart transplantation in patients who have had previous operations (29/81 in our series) or in patients receiving mechanical circulatory support (10/81 in our series), the alternative technique appears to be more convenient; the impaired right atrium is completely excised, and the 
Table III-A. Hemodynamic parameters at day 1 in 81 heart transplantations: group I (standard) and group II (caval anastomoses)

\begin{tabular}{lccc}
\hline & $\begin{array}{c}\text { Group I } \\
(n=40)\end{array}$ & $\begin{array}{c}\text { Group II } \\
(n=41)\end{array}$ & $\begin{array}{c}\text { Statistical } \\
\text { significance }\end{array}$ \\
\hline HR (beats/min) & $107 \pm 11.6$ & $119 \pm 16$ & $p=0.01$ \\
MAP (mm Hg) & $82 \pm 15.2$ & $85 \pm 15.8$ & $\mathrm{NS}$ \\
RAP (mm Hg) & $13 \pm 4$ & $12.6 \pm 7$ & $\mathrm{NS}$ \\
MPAP (mm Hg) & $27 \pm 2.1$ & $23.5 \pm 6.5$ & $p=0.001$ \\
PCWP (mm Hg) & $12 \pm 4$ & $12.7 \pm 5$ & $\mathrm{NS}$ \\
CI (L/min per square meter) & $3.77 \pm 0.65$ & $4.12 \pm 0.85$ & $p=0.04$ \\
\hline
\end{tabular}

$H R$, Heart rate; $M A P$, mean aortic pressure; $R A P$, right atrial pressure; $M P A P$, mean pulmonary artery pressure; $P C W P$, pulmonary capillary wedge pressure; $C I$, cardiac index; $N S$, not significant.

Table III-B. Hemodynamic parameters at day 2 in 79 heart transplantations: group I (standard) and group II (caval anastomoses)

\begin{tabular}{lccc}
\hline & $\begin{array}{c}\text { Group I } \\
(n=39)\end{array}$ & $\begin{array}{c}\text { Group II } \\
(n=40)\end{array}$ & $\begin{array}{c}\text { Statistical } \\
\text { significance }\end{array}$ \\
\hline HR (beats/min) & $103 \pm 9.9$ & $112 \pm 11.4$ & $p=0.01$ \\
MAP (mm Hg) & $84 \pm 14$ & $84 \pm 16$ & NS \\
RAP (mm Hg) & $14 \pm 2.5$ & $15 \pm 5$ & NS \\
MPAP (mm Hg) & $27 \pm 3.2$ & $24.4 \pm 4.4$ & $p=0.005$ \\
PCWP (mm Hg) & $12.7 \pm 2.6$ & $12.5 \pm 4.2$ & NS \\
CI (L/min per square meter) & $3.78 \pm 0.85$ & $4.03 \pm 1$ & NS \\
\hline
\end{tabular}

Two patients died on the first postoperative day. For abbreviations see Table III-A.

venae cavae are easy to manipulate. In case of considerable size mismatch between donor and recipient, a growing problem because of donor graft shortage, ${ }^{13}$ distance between the two trimmed venae cavae in the thorax remains almost identical although the right atrial size can be considerably different. This is another advantage of the alternative technique with its bicaval anastomoses.

Most important of all, this technique can offer a return to sinus rhythm in $100 \%$ of patients, avoiding asynchronous atrial contractions and conduction abnormalities that lead to pacemaker implantation in the standard technique, a rate of $15 \%$ in some series, ${ }^{3,14}$ and to the obvious risk of sudden death.

Heart transplantation with bicaval anastomoses, keeping the right atrium intact and modifying the left atrium to a minor degree, should be considered the optimal procedure. It is technically easy to do, even simpler than the standard procedure in certain situations, and it lowers the morbidity of heart transplantation, particularly postoperative rhythm disorders.

Even though major improvements in outcome are not yet apparent, a higher number of these alternative procedures in multicenter studies should prove the advantage of bicaval anastomoses in the near future.

\section{REFERENCES}

1. Lower RR, Stofen RR, Shumway NE. Homovital transplantation of the heart. J THORAC CARDIOVASC SURG 1961:41:196.

2. Angermann CE, Spes CH, Tammew A, et al. Anatomic characteristics and valvular function of the transplanted heart: transthoracic versus transesophageal echocardiographic findings. J Heart Lung Transplant 1990;9:331-8.

3. Stevenson LW, Dadourian BJ, Kobashigawa J, Child JS, Clark SH, Laks H. Mitral regurgitation after cardiac transplantation. Am J Cardiol 1987;60:119-22.

4. Kaye DM, Anderson ST, Federman J. Electrocardiographic and echocardiographic features of left atrial size after orthotopic cardiac transplantation. Am J Cardiol 1992;70:1096-9.

5. Fernandez-Gonzales AL, Llorens R, Herreros JM, et al. Intracardiac thrombi after orthotopic heart transplantation: clinical significance and etiologic factors. J Heart Lung Transplant 1994;13:236-40.

6. Dreyfus G, Jebara V, Mihaileanu S, Carpentier AF. Total orthotopic heart transplantation: an alternative to the standard technique. Ann Thorac Surg 1991;52: $1181-4$.

7. Kendall SWH, Ciulli F, Mullins PA, Biocina B, Dunning JJ, Large SR. Total orthotopic heart transplantation: an alternative to the standard technique [Letter]. Ann Thorac Surg 1992;54:187-8.

8. Sarsam MA, Campbell CS, Yonan NA, Deiraniya 
AK, Rochman AN. An alternative surgical technique in orthotopic cardiac transplantation. J Card Surg 1993;8:344-9.

9. Blanche C, Czer LS, Valenza M, Trento A. Alternative technique for orthotopic heart transplantation. Ann Thorac Surg 1994;57:765-7.

10. Bizouarn P, Treilhaud M, Portier D, Train M, Michaud JL. Right ventricular function early after total or standard orthotopic heart transplantation. Ann Thorac Surg 1994;57:183-7.

11. France-Transplant: Etude interface Société Française de Transplantation/France-Transplant. Rapport 1993.
12. Hosenpud JD, Novick RJ, Breen TJ, Daily PO. The Registry fof the I.S.H.L.T.: eleventh official report 1994. J Heart Lung Transplant 1994;13:561-70.

13. Deleuze PH, Mazzucotelli JP, Benvenuti $\mathrm{C}$, et al. Donor/recipient size mismatch in heart transplantation: a technical alternative. J Card Surg 1994;9: 70-3.

14. Rosado LJ, Huston CL, Sethi GK, Copeland JG. Sinoatrial node dysfunction in recipients of domino heart transplants: complication of a surgical harvesting technique. J Heart Lung Transplant 1992;11:107881 .

\section{Availability of JournaL back issues}

As a service to our subscribers, copies of back issues of THE JOURNal OF THORACIC AND CARDIOVASCULAR SURGERy for the preceding 5 years are maintained and are available for purchase from the publisher, Mosby-Year Book, Inc., at a cost of $\$ 12.00$ per issue. The following quantity discounts are available: $25 \%$ off on quantities of 12 to 23 , and one third off on quantities of 24 or more. Please write to Mosby-Year Book, Inc., Subscription Services, 11830 Westline Industrial Drive, St. Louis MO 63146-3318, or call (800)453-4351 or (314)453-4351 for information on availability of particular issues. If unavailable from the publisher, photocopies of complete issues are available from University Microfilms International, 300 N. Zeeb Rd., Ann Arbor, MI 48106 , (313) $761-4700$. 